\title{
Erratum to: Exogenous orienting of crossmodal attention in 3-D space: Support for a depth-aware crossmodal attentional system
}

\author{
N. Van der Stoep • T. C. W. Nijboer • S. Van der Stigchel
}

Published online: 23 April 2014

(C) Psychonomic Society, Inc. 2014

\section{Erratum to: Psychon Bull Rev}

DOI 10.3758/s13423-013-0532-y

We wish to correct two points in our published work:

At page 2 (at the top left of the page) of the article we mention that there is a study that looked into endogenous crossmodal orienting of attention, but the study we refer to concerns endogenous intramodal orienting of attention.

"...In the one study that did look into crossmodal orienting of attention to different frontal depth planes, endogenous crossmodal attention was manipulated (Couyoumdjian, Di Nocera, \& Ferlazzo, 2003; see

Downing \& Pinker, 1985, for intramodal endogenous attention in frontal depth)."

This sentence should be removed and replaced with:

"Studies that did look into attentional shifts to different planes in frontal depth either concerned exogenous or endogenous intramodal orienting of attention (see for example Downing \& Pinker, 1985, and Couyoumdjian, Di Nocera, \& Ferlazzo, 2003 for intramodal endogenous attention in frontal depth)."

The second point concerns the effect sizes that are mentioned in the Results and discussion section of the article (Response times section). We reported effect sizes as eta squared $\left(\eta^{2}\right)$, but the reported effect sizes are in fact partial eta squared (partial $\left.\eta^{2}\right)$.

The online version of the original article can be found at http:// dx.doi.org/10.3758/s13423-013-0532-y.

N. Van der Stoep $(\bowtie) \cdot$ T. C. W. Nijboer $\cdot$ S. Van der Stigchel Department of Experimental Psychology, Helmholtz Institute, Utrecht University, Heidelberglaan 2, 3584 CS Utrecht, The Netherlands

e-mail: N.VanderStoep@uu.nl

T. C. W. Nijboer

e-mail: T.C.W.Nijboer@uu.nl

S. Van der Stigchel

e-mail: S.VanderStigchel@uu.nl

T. C. W. Nijboer

Brain Center Rudolf Magnus and Center of Excellence for

Rehabilitation Medicine, University Medical Center Utrecht and

De Hoogstraat Rehabilitation, Utrecht, The Netherlands 